\title{
KOMPOSISI JENIS IKAN HASIL TANGKAPAN SAMPINGAN (BYCATCH) PUKAT DORONG DI TAMBAK LOROK, SEMARANG
}

\author{
Bycatch Type Composition of Pushnet in The Tambak Lorok, Semarang
}

\author{
Laeli Luthfiani, Abdul Ghofar*), dan Frida Purwanti
}

Program Studi Manajemen Sumberdaya Perairan, Departemen Sumberdaya Akuatik

Fakultas Perikanan dan Ilmu Kelautan, Universitas Diponegoro

Jl. Prof. Soedarto, SH, Tembalang, Semarang, Jawa Tengah - 50275, Telp/Fax. +6224 7474698

Email : laeliluthfiani@gmail.com

\begin{abstract}
ABSTRAK
Kegiatan perikanan tangkap di Tambak Lorok dilakukan menggunakan berbagai alat tangkap, salah satunya adalah pukat dorong / sodo. Penggunaan pukat dorong menghasilkan tangkapan sampingan (bycatch). Penelitian dilaksanakan pada Desember 2017 - Maret 2018 di Tambak Lorok, Semarang. Penelitian bertujuan untuk mengetahui cara pengoperasian pukat dorong, komposisi hasil tangkapan, komposisi jenis, dan distribusi ukuran hasil tangkapan sampingan pukat dorong di Tambak Lorok, Semarang. Metode penelitian yang digunakan adalah metode survey, sedangkan pengambilan sampel dilakukan dengan metode purposive sampling. Sampling dilakukan sebanyak 5 kali dengan mendata hasil tangkapan kapal pukat dorong di dermaga dan 1 kali mengikuti kegiatan nelayan dalam operasi penangkapan ikan. Pengoperasian pukat dorong meliputi proses setting, pushing, dan hauling selama 6 jam pada kedalaman 5-12 meter sekitar 2 mil dari bibir pantai dengan nilai B/C Ratio yaitu 1,63 yang berarti usaha tersebut menghasilkan keuntungan sehingga layak untuk dijalankan. Komposisi hasil tangkapan pukat dorong berdasarkan berat tangkapan yaitu 39,84\% tangkapan utama dan 60,16\% tangkapan sampingan. Hasil tangkapan sampingan pukat dorong yang sering ditemukan adalah Ikan Layur (Trichiurus lepturus), Ikan Kempar (Secutor ruconius), Ikan Kembung (Rastrelliger sp.), dan Ikan Tunul (Sphyraena jello). Distribusi ukuran beberapa jenis tangkapan sampingan merupakan ukuran yang belum layak tangkap karena $<\mathrm{Lm}$ dan nilai $\mathrm{L} 50 \%<1 / 2 \mathrm{~L} \infty$.
\end{abstract}

Kata Kunci: Komposisi Jenis, Hasil Tangkapan Sampingan, Pukat Dorong, Tambak Lorok, Semarang

\section{ABSTRACT}

Capture fisheries in the Tambak Lorok use a variety of fishing gear; one of which is pushnet / sodo. The use of pushnet produces bycatch. The research was conducted in December 2017 - March 2018 aiming to find out the way of pushnet operation, catch composition, bycatch type composition, and bycatch size distribution of pushnet in the Tambak Lorok, Semarang. The research method used survey method, while sampling done by purposive sampling method. Operation of pushnet includes the process of setting, pushing, and hauling for 6 hours at a depth of 5-12 meters about 2 miles away from the shore. The value of $B / C$ Ratio is 1.63 which means the business is feasible. Catches composition by weight is 39,84\% target species and 60,16\% bycatch. Composition type of bycatch was dominated by Ribbonfish (Trichiurus lepturus), Ponyfish (Secutor ruconius), Mackerel (Rastrelliger sp.), and Barracuda (Sphyraena jello). The size distribution of some bycatch were included the size of uncatchable fish because $<$ Lm and $L 50 \%<1 / 2 L \infty$.

Keywords: Type Composition, Bycatch, Pushnet, Tambak Lorok, Semarang

*) Penulis Penanggung Jawab

\section{PENDAHULUAN}

Kegiatan perikanan tangkap di sekitar perairan Tambak Lorok dilakukan oleh alat tangkap dimana salah satunya adalah pukat dorong/sodo (pushnet). Pukat dorong merupakan jenis alat tangkap yang dianggap sederhana dan menguntungkan oleh nelayan setempat. Pushnet adalah jenis alat tangkap yang dioperasikan dengan mendorongnya berdasarkan bantuan kapal maupun tidak di permukaan perairan ataupun di dasar perairan. Untuk membuka mulut jaring diperlukan kayu/bambu yang dipasang pada pojok jaring agar membentuk segitiga. Ukuran dan bentuk pukat dorong sangat beragam termasuk alat bantu yang digunakan (Zarochman et al., 2009). Namun pukat dorong tergolong alat tangkap yang dilarang pengoprasiannya menurut Peraturan Menteri Kelautan dan Perikanan No. 71 Tahun 2016. Alat tangkap yang digunakan dalam perikanan udang tidak selektif dan cenderung merusak. Salah satunya adalah pushnet (pukat dorong) (Udoh dan Ukpatu, 2017). Peningkatan upaya penangkapan ikan, penggunaan pukat dorong memiliki dua efek. Pertama, tingginya hasil bycatch mempengaruhi fungsi 
pemijahan dan restocking dari suatu perairan. Kedua, kondisi durasi kecepatan dan pendorongan dapat menyebabkan cedera, yang mungkin menghasilkan mortalitas pada daerah operasi penangkapan. Sehingga organisme yang tidak tertangkappun ikut menerima dampaknya (Briand et al., 2012).

Hasil tangkapan pukat dorong terdiri dari dua jenis yaitu hasil tangkapan utama (target species) dan hasil tangkapan sampingan (bycatch). Hasil tangkapan sampingan adalah tangkapan yang tidak diinginkan namun tertangkap selama operasi penangkapan ikan. Bycatch merupakan salah satu isu yang cukup mengganggu pada pengelolaan sumberdaya perikanan secara berkelanjutan. Upaya untuk mengurangi hasil tangkapan sampingan yang tidak diinginkan perlu dilakukan studi lebih lanjut. Menurut FAO (2011) tentang International Guidelines on Bycatch Management and Reduction of Discards menyebutkan bahwa berbagai masalah mengenai bycatch telah diakui dalam perikanan tangkap yang spesifik, beberapa contoh antara lain yaitu: (1) jenis spesies dan ukuran yang tidak secara khusus ditargetkan dalam perikanan, (2) spesies yang dilindungi, dan atau terancam punah, (3) ikan juvenil, dan (4) organisme yang tidak diharapkan (no intended use).

Hasil tangkapan sampingan yang dihasilkan oleh kegiatan perikanan tangkap cukup besar. Ardill et al. (2013) memperkirakan bahwa rata-rata 27 juta ton ikan dibuang setiap tahunnya, setara dengan $30 \%$ dari ikan yang didaratkan dunia, walaupun ada laporan yang menyatakan bahwa beberapa ikan ini mungkin telah didaratkan dan dikonsumsi. Bahkan WWF (2013) dalam Nugraha dan Setyadji (2013) memperkirakan bahwa setidaknya $40 \%$ atau 38 juta ton tangkapan laut dunia tahunan adalah berupa hasil tangkapan sampingan. Melihat tingginya persentase hasil tangkapan sampingan tersebut, maka perlu adanya pendekatan perikanan bernuansa ramah lingkungan. Hal ini dimaksudkan agar hasil tangkapan sampingan dapat direduksi jumlahnya serta melindungi perairan dari aktifitas penangkapan yang merusak lingkungan.

Keberadaan hasil tangkapan sampingan merupakan kontribusi dari rendahnya selektivitas suatu alat tangkap serta menjadi karakteristik dari daerah penangkapan ikan yang bersifat multi spesies (Slavin, 1982; Kelleher, 2005). Perlu adanya suatu identifikasi secara kontinyu untuk mengestimasi jumlah spesies ikan yang tertangkap di Perairan Utara Jawa. Data tersebut meliputi spesies yang dikategorikan sebagai komersial dan spesies yang tidak dimanfaatkan (discard). Estimasi setiap tahun perlu dilakukan untuk hasil tangkap sampingan dan yang dibuang kelaut, serta identifikasi terhadap spesies yang dikategorikan sebagai spesies yang perlu mendapat prioritas. Karakterisasi dari hasil tangkap sampingan perlu dilakukan mengingat perikanan di Indonesia merupakan multispesies yang dipengaruhi secara spasial dan temporal serta lingkungan perairan. Sehingga perlu dilakukan suatu pembagian wilayah berupa sub area yang membagi setiap WPP sehingga setiap sub area memberikan informasi yang lebih akurat (Wahju, 2012).

Penelitian ini bertujuan untuk mengetahui pengoperasian pukat dorong, komposisi hasil tangkapan, komposisi jenis, dan distribusi ukuran hasil tangkapan sampingan pukat dorong di Tambak Lorok, Semarang.

\section{MATERI DAN METODE}

\section{A. Waktu dan Tempat}

Penelitian dilaksanakan pada tanggal 25 Desember 2017 - 16 Maret 2018 di Tambak Lorok, Semarang. Sampling dilakukan sebanyak lima kali dengan mendata jenis hasil tangkapan yang didaratkan di PPI Tambak Lorok dan satu kali mengikuti kegiatan nelayan dalam operasi penangkapan ikan pada bulan Februari 2018. Identifikasi dan pengukuran hasil tangkapan dilakukan di lapangan, namun untuk jenis-jenis tertentu yang sulit diketahui maka di identifikasi dan diukur di Laboratorium Biologi Fakultas Perikanan dan Ilmu Kelautan, Universitas Diponegoro.

\section{B. Pengumpulan Data}

Metode dalam pengambilan data yaitu metode survey dan pengambilan sampel dilakukan dengan metode purposive sampling. Pengumpulan data dilakukan dengan cara primer dan sekunder. Data primer diperoleh dari identifikasi jenis ikan di Tambak Lorok, Semarang saat bongkar muat kapal dan mengikuti kegiatan operasi penangkapan ikan oleh nelayan pukat dorong. Data sekunder diperoleh dari Dinas Kelautan dan Perikanan Semarang terkait perkembangan jumlah alat tangkap pukat dorong di Tambak Lorok, Semarang.

Sampel tangkapan diambil 10\% dari total hasil tangkapan tiap kapal (Saputra et al., 2013). Penentuan kapal sampel mengikuti prosedur yang dikemukakan oleh Wahyuni et al. (2017) yaitu sebagai berikut:

a. Jika kapal yang mendarat kurang dari 5 buah, dipilih satu kapal yaitu kapal nomor satu;

b. Jika kapal yang datang lebih dari 5 buah, maka dipilih 2 buah kapal sebagai kapal sampel. Kapal sampel pertama adalah kapal nomor urut 1 dari daftar nomor urut kapal. Kapal sampel kedua adalah kapal nomor 2 yang daerah penangkapannya berbeda dengan kapal nomor 1.

\section{Analisis Data}

\section{a. Analisis Data Komposis Jenis}

Komposisi jenis ikan hasil tangkapan dianalisis dan disajikan dalam grafik histogram berdasarkan jenis ikan hasil tangkapan utama dan ikan hasil tangkapan sampingan (Astuti et al., 2016). Penentuan komposisi jenis dilakukan identifikasi dengan pengamatan morfologi pada ikan yang tertangkap oleh pukat dorong. Pengamatan morfologi ini menggunakan buku acuan identifikasi FAO Catalogue for Fishery Purposes. Data komposisi jenis kemudian diolah dengan menggunakan software Microsoft Excel 2007. Hasil dari analisa data akan disajikan dalam bentuk tabel dan grafik/diagram. 


\section{b. Analisis Proporsi Hasil Tangkapan Sampingan (Bycatch)}

Analisis proporsi hasil tangkapan sampingan dilakukan dengan membandingan antara jumlah hasil tangkapan target dan non target. Analisis terhadap jumlah hasil tangkapan disajikan dalam bentuk diagram.

\section{c. Analisis Komposisi Ukuran Hasil Tangkapan}

Analisis komposisi ukuran hasil tangkapan dilakukan dengan mengolah hasil pengukuran panjang total (total length) ikan. Hasil pengukuran panjang total ikan dikelompokkan dalam selang kelas panjang dan interval kelas. Menurut Nugroho et al. (2015) untuk menentukan jumlah selang kelas panjang dan interval kelas dihitung dengan menggunakan rumus distribusi frekuensi, yaitu:

Keterangan :

$$
\begin{aligned}
\mathrm{K} & =1+3,3 \log n \\
\text { Lebar kelas }(\mathrm{i}) & =\frac{\text { Nilai terbesar }- \text { Nilai terkecil }}{K}
\end{aligned}
$$

$\mathrm{K} \quad$ : jumlah kelas

n : banyaknya data

Hasil pengolahan data ukuran panjang yang disajikan kedalam bentuk sebaran frekuensi, akan memudahkan dalam menganalisis pada selang kelas mana ikan sebagai hasil tangkap sampingan kebanyakan tertangkap dan dapat digunakan untuk menentukan layak atau tidaknya ikan tersebut untuk ditangkap (Nugroho et al., 2015).

Menurut Widodo et al. (2010) ukuran pertama kali (L50\%) tertangkap hasil tangkapan pukat dorong diketahui dengan memplotkan persentase frekuensi komulatif hasil tangkapan dengan 50\% ukuran panjang totalnya, dimana titik potong antara kurva dengan 50\% frekuensi kumulatif adalah panjang saat 50\% udang tertangkap. Panjang infinity $(\mathrm{L} \infty)$ dihitung untuk mengetahui ukuran rata-rata panjang udang pada umur sangat tua. Menurut Wahyuni et al. (2017) apabila L50\% < Lo maka ukuran hasil tangkapan terlalu kecil sehingga dikhawatirkan terjadi growth overfishing. Perhitungan panjang infinity sebagai berikut:

Keterangan:

$$
\mathrm{L} \infty=\frac{\mathrm{Lmaks}}{0,95}
$$

Lmaks : panjang maksimum

L $\infty \quad$ : Panjang infinity

\section{HASIL DAN PEMBAHASAN}

HASIL

a. Pengoperasian Pukat Dorong (Pushnet)

Pengoperasian alat tangkap pukat dorong terdiri dari proses setting, pushing, dan hauling. Setting adalah kegiatan penurunan alat tangkap, pushing adalah pendorongan alat tangkap sodo ketika alat tangkap dioperasikan, dan hauling adalah penarikan alat tangkap. Setiap proses tersebut membutuhkan waktu yang berbeda-beda. Berikut merupakan peta lokasi penelitian pukat dorong di Tambak Lorok, semarang tersaji pada Gambar 1.
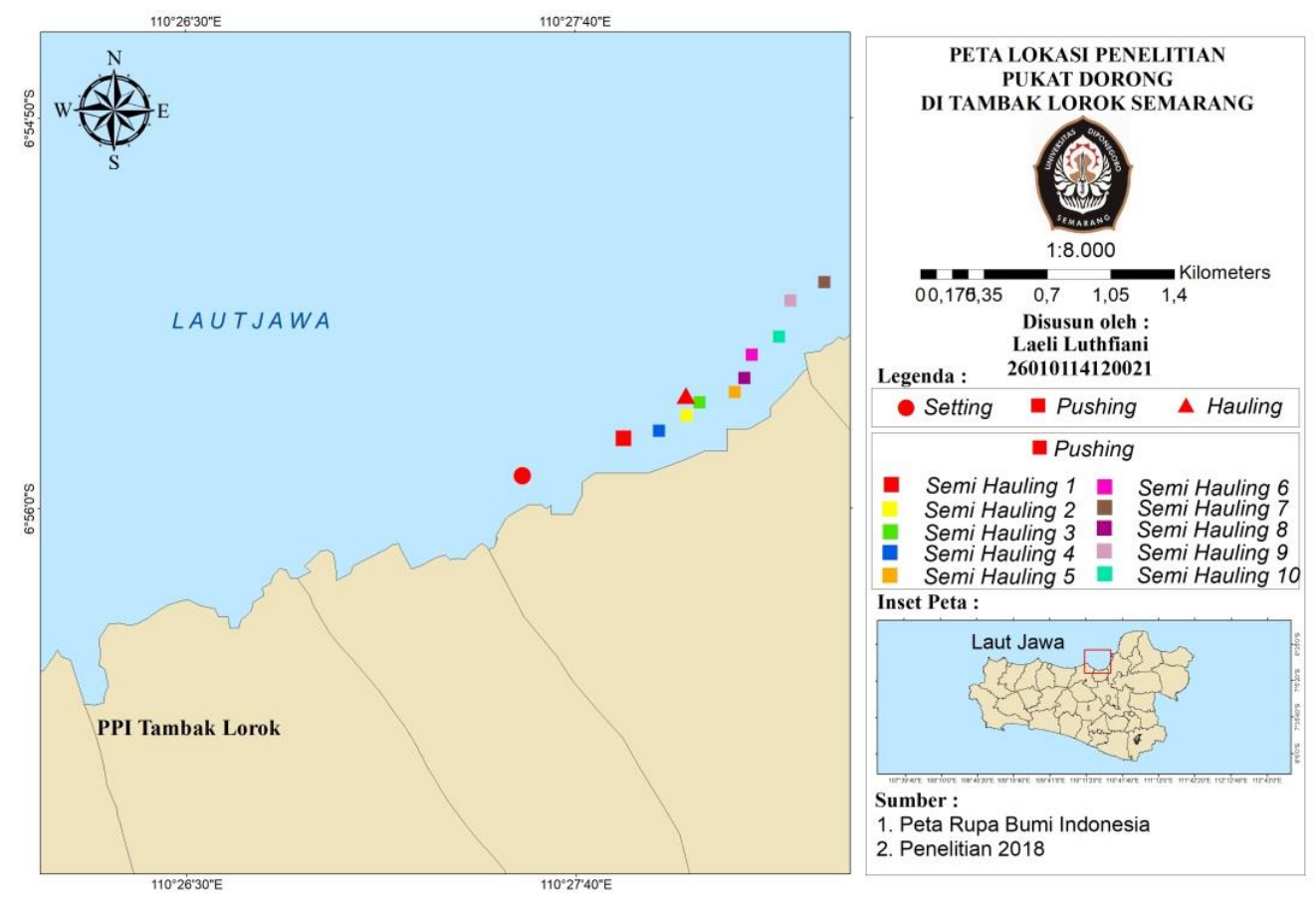

Gambar 1. Peta Lokasi Penelitian, Titik Setting, Pushing dan Hauling Pukat Dorong (Pushnet) di Tambak Lorok, Semarang 


\section{b. Komposisi Hasil Tangkapan Pukat Dorong (Pushnet)}

Hasil tangkapan utama (target species) dengan non-target species yaitu hasil tangkapan sampingan berdasarkan rata - rata total berat tangkapan tersaji Gambar 2. Persentase antara hasil tangkapan utama dengan hasil tangkapan sampingan berdasarkan berat tangkapan yaitu 39,84\% untuk tangkapan utama dan 60,16\% untuk tangkapan sampingan.

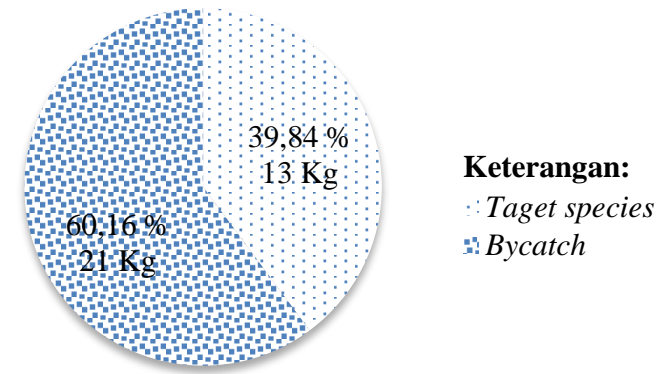

Gambar 2. Proporsi Berdasarkan Berat Hasil Tangkapan Pukat Dorong di Tambak Lorok, Desember - Maret 2018

Jenis ikan hasil tangkapan pukat dorong di Tambak Lorok tersaji pada Gambar 3. Jenis ikan yang ditemukan adalah 20 jenis. Jenis yang paling sering ditemukan yaitu Udang Putih (Penaeus merguiensis), Layur (Trichiurus lepturus), Udang Putih (Penaeus indicus), dan Udang Krosok (Metapenaeus tenuipes). Jenis Ikan yang paling sedikit ditemukan yaitu Ikan Semadar / Baronang (Siganus canaliculatus), dan Udang Pama (Penaeus semisulcatus)

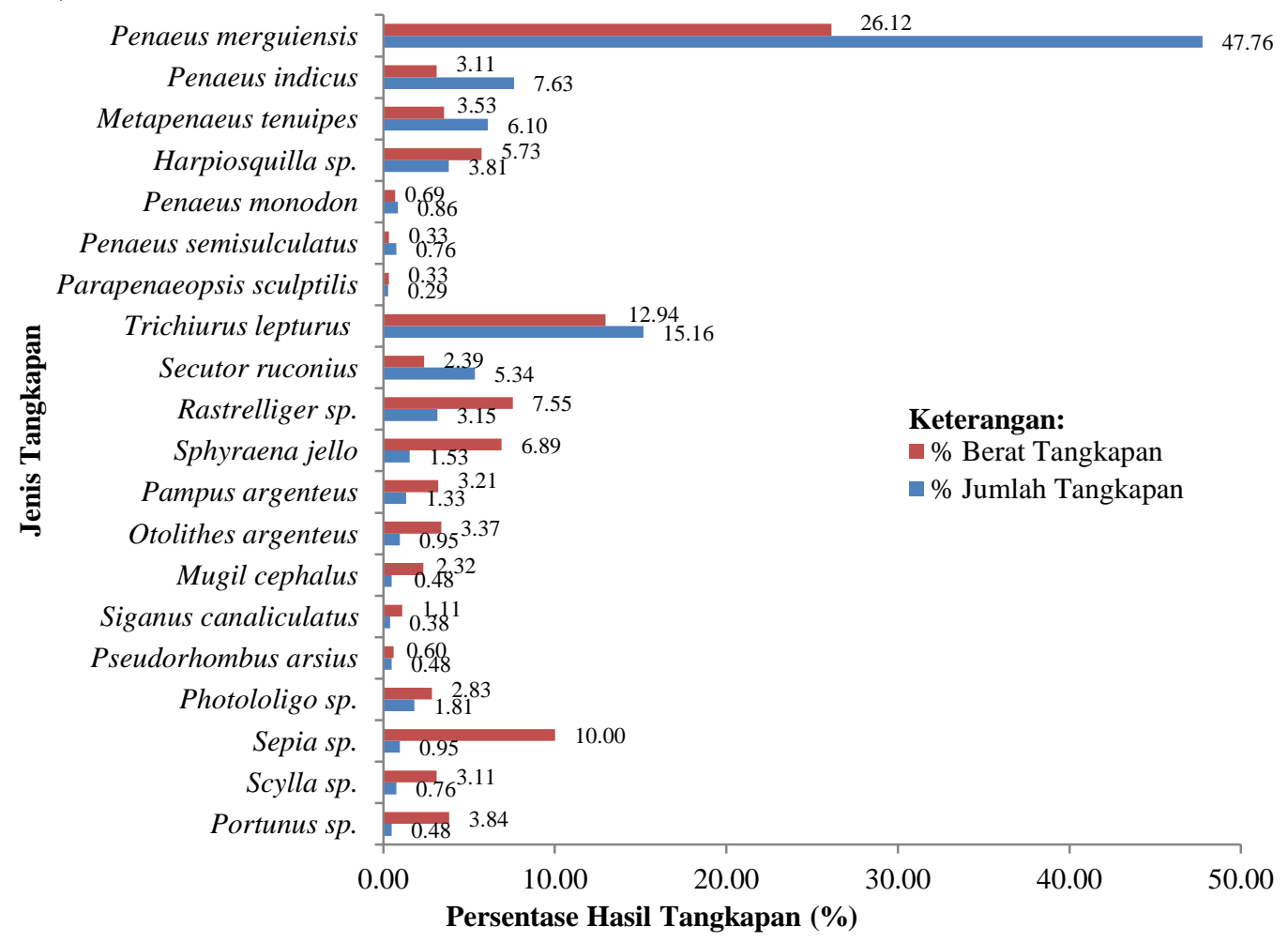

Gambar 3. Persentase Komposisi Hasil Tangkapan Pukat Dorong di Tambak Lorok, Desember - Maret 2018

c. Komposisi Hasil Tangkapan Utama Pukat Dorong (Pushnet)

Komposisi jenis hasil tangkapan utama pukat dorong berdasarkan jumlah dan berat tangkapan selama penelitian bulan Desember-Maret 2018 tersaji pada Gambar 4. Hasil tangkapan utama merupakan target utama dari setiap operasi penangkapan ikan. Hasil tangkapan utama pukat dorong di Tambak Lorok, Semarang adalah udang. Terdapat tujuh jenis hasil tangkapan utama pukat dorong selama penelitian bulan Desember - Maret 2018. Jenis tangkapan utama tersebut adalah Udang Putih ( $P$. merguiensis) 71,06\% untuk persentase jumlah tangkapan, Udang Putih (P. indicus) 11,35\%, Udang Krosok (M. tenuipes) 9,08\%, Udang Ronggeng (Harpiosquilla sp.) 5,67\%, dan Udang Windu ( $P$. monodon) 1,28\%. Persentase berat hasil tangkapan utama adalah Udang Putih (P. merguiensis) 65,58\%, Udang Ronggeng (Harpiosquilla sp.) 14,39\%, Udang Krosok (M. tenuipes) 8,86\%, Udang Putih ( $P$. indicus) $7,80 \%$, dan Udang Windu (P. monodon) $1,72 \%$. 


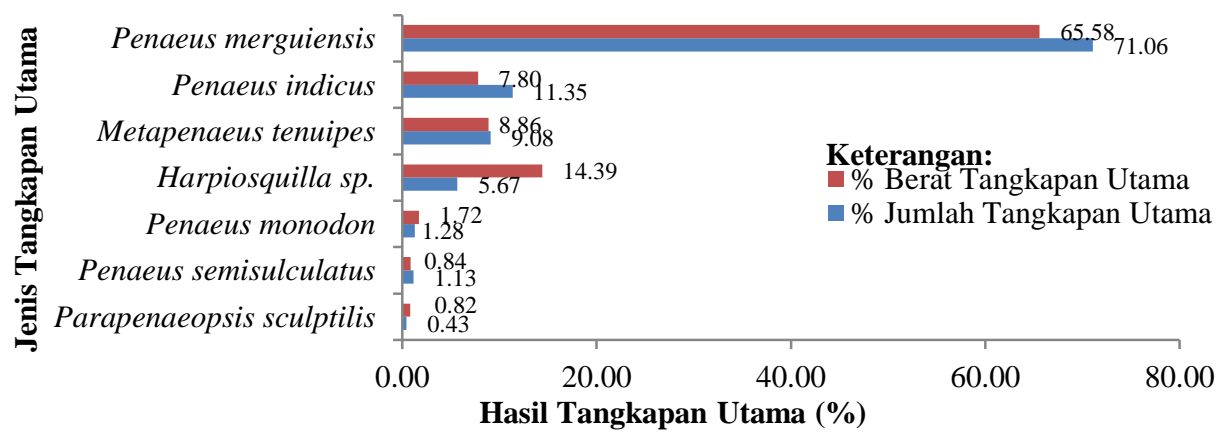

Gambar 4. Persentase Komposisi Hasil Tangkapan Utama Pukat Dorong di Tambak Lorok, Desember - Maret 2018

d. Komposisi Hasil Tangkapan Sampingan (Bycatch) Pukat Dorong (Pushnet)

Persentase komposisi berdasarkan jumlah dan berat hasil tangkapan sampingan pukat dorong selama penelitian bulan Desember-Maret 2018 tersaji pada Gambar 5. Jenis ikan hasil tangkapan sampingan lebih banyak dan beragam dari hasil tangkapan utama. Berdasarkan penelitian bulan Desember - Maret 2018 terdapat 13 jenis ikan hasil tangkapan sampingan.

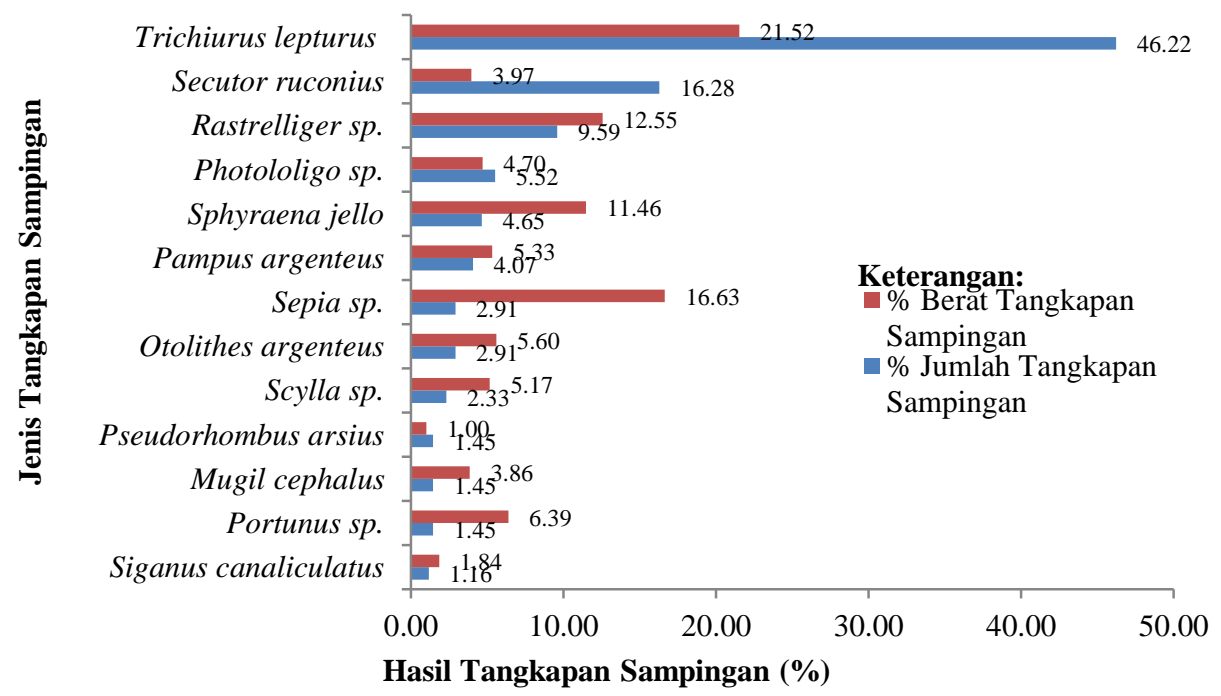

Gambar 5. Persentase Komposisi Hasil Tangkapan Sampingan Pukat Dorong di Tambak Lorok, Desember - Maret 2018

\section{e. Distribusi Ukuran Hasil Tangkapan Sampingan (Bycatch) Pukat Dorong (Pushnet)}

Berikut merupakan distribusi ukuran hasil tangkapan sampingan pukat dorong di Tambak Lorok, Desember-Maret 2018 tersaji pada Gambar 6. Grafik distribusi ukuran panjang total ikan hasil tangkapan sampingan pukat dorong meliputi ikan yang sering ditemukan selama penelitian. Ikan tersebut meliputi Ikan Layur ( $T$. lepturus), Ikan Kempar (S. ruconius), Ikan Kembung (Rastrelliger sp.), Ikan Tunul (S. jello), dan Ikan Bawal Putih $(P$. argenteus). Setiap jenis Ikan hasil tangkapan utama memiliki sebaran ukuran yang berbeda-beda. Penentuan panjang kelas, selang kelas panjang dan interval kelas dihitung dengan menggunakan rumus distribusi frekuensi menurut Nugroho et al. (2015).
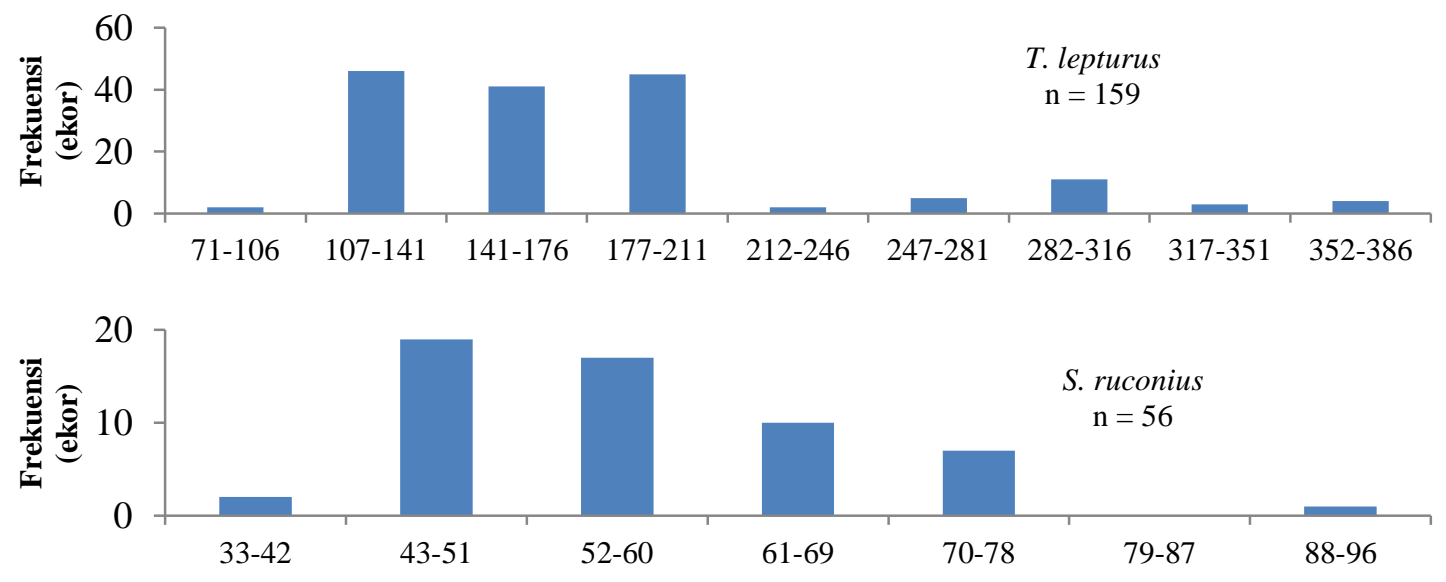

${ }^{\odot}$ Copyright by Management of Aquatic Resources (MAQUARES) 

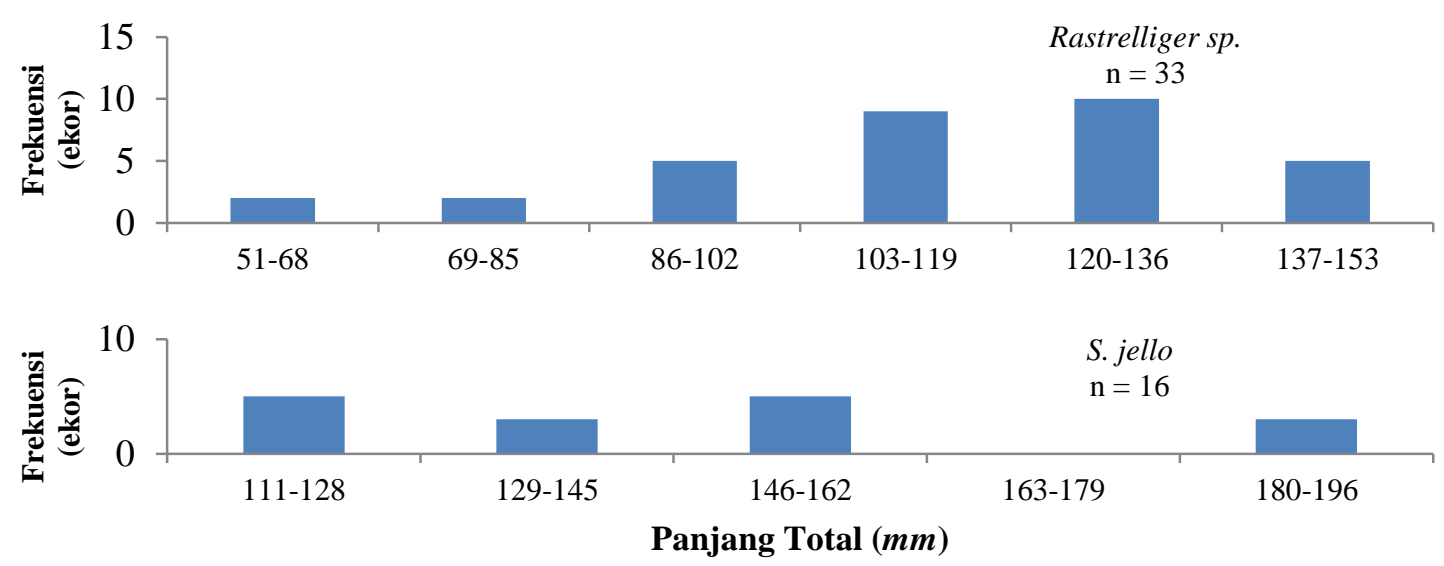

Gambar 6. Distribusi Ukuran Panjang Total (Total Length) Ikan Hasil Tangkapan Sampingan Pukat Dorong (Pushnet) di Tambak Lorok, Desember-Maret 2018

Ukuran pertama kali tertangkap ikan dominan hasil tangkapan sampingan pukat dorong di Tambak Lorok, Desember-Maret 2018 tersaji pada Gambar 7. dan Tabel 1. Ukuran pertama kali (L50\%) tertangkap Ikan Layur (T. lepturus) yaitu $170 \mathrm{~mm}$. Ukuran L50\% Ikan Layur (T. lepturus) $<1 / 2$ L $\infty$ sehingga dapat dikatakan belum layak tangkap. Sedangkan ukuran L50\% untuk Ikan Kempar (S. ruconius) dan Ikan Kembung (Rastrelliger sp.) L50\% lebih besar dari $1 / 2 \mathrm{~L} \infty$. Menurut penelitian Vianita et al. (2014) di Morodemak yaitu ukuran pertama kali tertangkapnya Ikan Layur adalah $563 \mathrm{~mm}$.

है

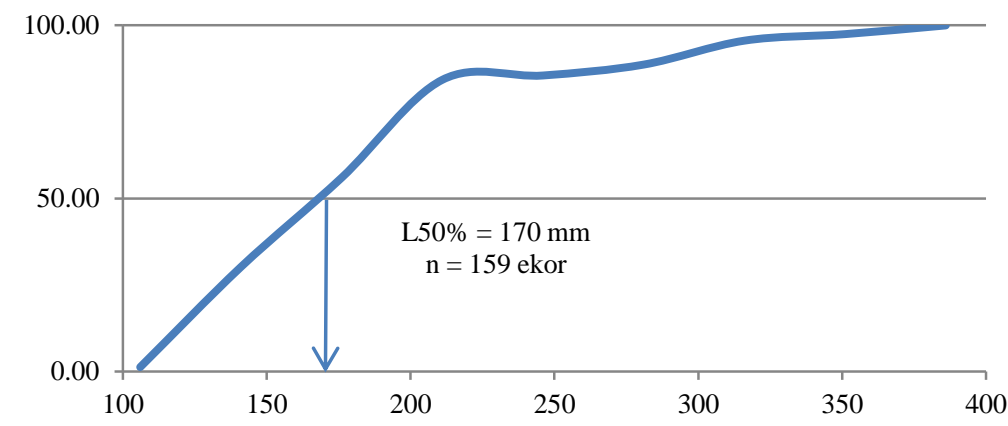

Total Length (mm) T. lepturus

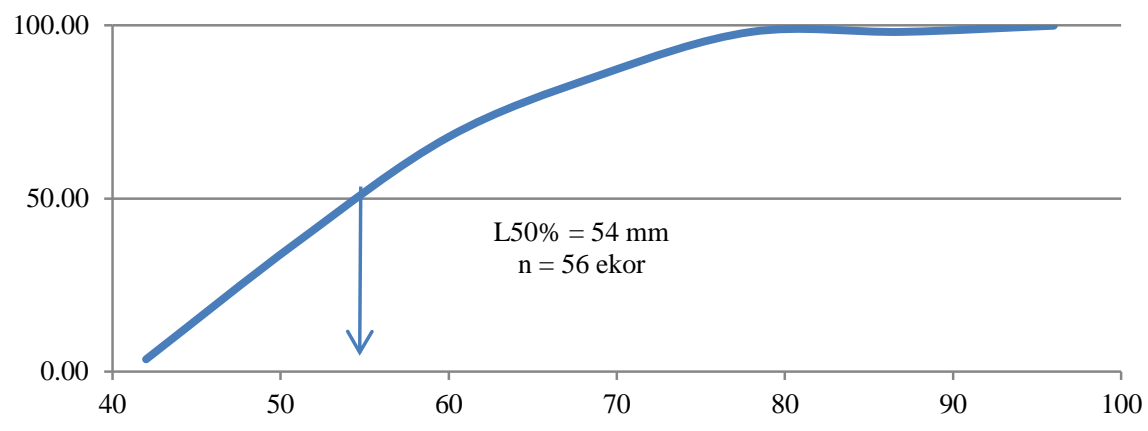

Total Length (mm) S. ruconius 


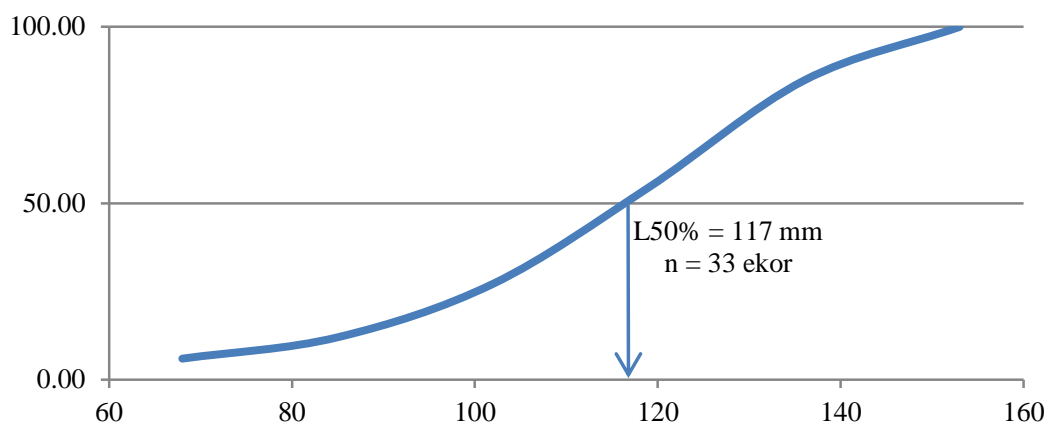

Total Length (mm) Rastrelliger sp.

Gambar 7. Ukuran Pertama Kali Tertangkap Ikan Hasil Tangkapan Sampingan Pukat Dorong di TambakLorok, Desember - Maret 2018

Tabel 1. Ukuran Pertama Kali Tertangkap (L50\%)

\begin{tabular}{lccccc}
\hline \multicolumn{1}{c}{ Jenis bycatch } & Lmaks $(\mathbf{m m})$ & L $\infty(\mathbf{m m})$ & $\begin{array}{c}\mathbf{1} / \mathbf{2} \mathbf{L} \infty \\
(\mathbf{m m})\end{array}$ & $\begin{array}{c}\text { L50\% } \\
(\mathbf{m m})\end{array}$ & Keterangan \\
\hline T. lepturus & 360 & 378,95 & 189,47 & 170 & $\mathrm{~L} 50 \%<1 / 2 \mathrm{~L} \infty$ \\
S. ruconius & 95 & 100,00 & 50,00 & 54 & $\mathrm{~L} 50 \%>1 / 2 \mathrm{~L} \infty$ \\
Rastrelliger sp. & 151 & 158,95 & 79,47 & 117 & $\mathrm{~L} 50 \%>1 / 2 \mathrm{~L} \infty$ \\
\hline
\end{tabular}

Sumber: Penelitian, 2018

\section{PEMBAHASAN}

\section{a. Pengoperasian Pukat Dorong}

Pengoperasian pukat dorong (pushnet) adalah dengan dengan mendorongnya berdasarkan bantuan kapal maupun tidak. Pukat dorong yang ada di tambak lorok merupakan pukat dorong berkapal. Hasil Rata - rata pendapatan nelayan pukat dorong dalam satu kali operasi penangkapan adalah Rp. 984.800 dimana Rp. 528.500 untuk tangkapan utama dan Rp. 456.300 untuk tangkapan sampingan. Biaya operasi meliputi biaya solar, perbekalan, dan es batu berkisar antara Rp. 150.000,- - Rp. 250.000,-. Usaha penangkapan pukat dorong di Tambak Lorok menghasilkan pendapatan pertahun sebesar Rp. 177.264.000 dengan total biaya pertahun Rp. 108.483.333. Berdasarkan hal tersebut nelayan pukat dorong memperoleh keuntungan pertahun sebesar Rp. 68.780.667. Hasil analisis kelayakan usaha menunjukan bahwa nilai B/C Ratio yaitu 1,63 yang berarti usaha tersebut menghasilkan keuntungan sehingga layak untuk dijalankan. Hal ini diperkuat oleh penelitian Kusuma et al., (2017) bahwa nilai B/C Ratio pada usaha penangkapan udang dengan pukat dorong di Tambak Lorok adalah 1,35 sehingga usaha layak untuk diteruskan karena nilai B/C Ratio lebih dari 1.

Daerah penangkapan pukat dorong berkisar antara perairan pantai semarang khususnya tambak Lorok hingga mendekati perairan Demak seperti tertuang pada Gambar 1. Perairan pantai dipilih karena pukat dorong terbatas beroperasi pada perairan yang dangkal yaitu sekitar dengan kedalaman 5-8 meter. Hal ini diperkuat oleh FAO (2013) bahwa pukat dorong didorong di bagian bawah perairan dangkal dan pesisir, di sepanjang pantai atau dari perahu.

Pukat dorong tergolong alat tangkap yang dilarang pengoprasiannya karena tidak ramah lingkungan. Hal ini didasarkan pada metode penangkapannya yaitu aktif mendorong sampai ke dasar perairan dan dioperasikan di perairan dangkal seperti pantai. Pengoperasian di perairan dangkal hingga mengeruk hasil perikanan di dasar perairan mampu menyebabkan kerusakan habitat biota dasar, pemborosan sumberdaya, serta dapat merusak keanekaragaman. Pengoperasian pukat dorong telah dilarang di perairan laut Indonesia menurut Peraturan Menteri Kelautan dan Perikanan No. 71 tahun 2016 tentang jalur penangkapan ikan dan penempatan alat penangkapan ikan di wilayah pengelolaan perikanan Negara Republik Indonesia.

\section{b. Komposisi Hasil Tangkapan Pukat Dorong}

Hasil tangkapan pukat dorong terbagi menjadi hasil tangkapan utama (target species) dan hasil tangkapan sampingan (bycatch). Hasil tangkapan pukat dorong selama penelitian di Tambak Lorok, Desember - Maret 2018 terdapat 7 jenis hasil tangkapan utama, 13 jenis hasil tangkapan sampingan. Menurut penelitian oleh Udoh dan Ukpatu (2017) menunjukan bahwa usaha penangkapan menghasilkan 85\% hasil tangkapan terdiri dari udang (tujuh spesies udang) dengan $14 \%$ bycatch. Bycatch umumnya terdiri dari ikan juvenil dan 0,81\% merupakan kepiting/cumi.

Hasil tangkapan pukat dorong yaitu Udang Putih ( $P$. merguiensis), Udang Putih ( $P$. indicus), Udang Krosok (M. tenuipes), Udang Ronggeng/Mantis (Harpiosquilla sp.), Udang windu (P. monodon), Ikan Layur (T. lepturus), Ikan Kempar (S. ruconius), Ikan Kembung (Rastrelliger sp.), Cumi (Photololigo sp.), Ikan Tunul ( $S$. jello), Ikan Bawal Putih ( $P$. argenteus), Sotong (Sepia sp.), Ikan Gerabah (O. argenteus), Kepiting (Scylla sp.) Ikan Sebelah (P. arsius), Ikan Belanak (M. cephalus), Rajungan (Portunus sp.), dan Ikan Baronang/Semadar ( $S$. canaliculatus). FAO (2000) menyebutkan bahwa pukat udang di Indonesia khususnya Laut Arafura (Indonesia 
Timur) menghasilkan udang tangkapan berupa udang Penaeid. Hasil tangkapan utama tersebut antar lain banana shrimp (P. indicus, P. merguiensis) 35,1\%; tiger shrimp (P.semisulcatus) 23,6\%; dan Metapaneus ensis 23,2\%. Menurut laporan ICES (International Council for the Exploration of the Sea) (2005), sebanyak 50\% dari hasil tangkapan udang terdiri dari Udang Putih (P. merguiensis) dan Metapaneus dengan alat tangkap trawl dan pushnet.

Berdasarkan hasil penelitian bulan Desember - Maret 2018, persentase komposisi hasil tangkapan sampingan lebih tinggi dari pada tangkapan utama. Komposisi tangkapan pukat dorong selama penelitian yaitu yaitu $39,84 \%$ untuk tangkapan utama dan $60,16 \%$ untuk tangkapan sampingan. Tingginya hasil tangkapan sampingan yang dihaslikan pukat dorong disebabkan oleh pukat dorong merupakan alat tangkap yang aktif dan kurang selektif. Ukuran mesh size pada kantong jaring pukat dorong di Tambak Lorok berkisar 0,5 - 0,75 inci. Hal tersebut sejalan menurut Udoh dan Ukpatu (2017) yang menyatakan bahwa alat tangkap yang digunakan dalam perikanan udang tidak selektif dan cenderung merusak. Salah satunya adalah pushnet.

\section{c. Komposisi Hasil Tangkapan Sampingan (Bycatch) Pukat Dorong}

Hasil tangkapan sampingan pukat dorong selama penelitian Desember-Maret 2018 di Tambak Lorok yaitu Ikan Layur (Trichiurus lepturus), Ikan Kempar (Secutor ruconius), Ikan Kembung (Rastrelliger sp.), Cumi (Photololigo sp.), Ikan Tunul (Sphyraena jello), Ikan Bawal Putih (Pampus argenteus), Sotong (Sepia sp.), Ikan Gerabah (Otolithes argenteus), Kepiting (Scylla sp.) Ikan Sebelah (Pseudorhombus arsius), Ikan Belanak (Mugil cephalus), Rajungan (Portunus sp.), dan Ikan Baronang/Semadar (Siganus canaliculatus). Menurut Alverson et al. (1994), terdapat beberapa family ikan hasil tangkapan sampingan dari pukat udang tropis. Bycatch pukat udang tersebut antara lain dari family Trichiuridae, Sphyraenidae, Scrombidae, dll.

Hasil tangkapan sampingan yang paling tinggi dan sering diperoleh adalah Ikan Layur (Trichiurus lepturus). Ikan Layur (Trichiurus lepturus) termasuk dalam family Trichiuridae dimana ikan ini memiliki bentuk ramping dan panjang. Ikan Layur termasuk hasil tangkapan sampingan paling tinggi karena tergolong ikan demersal dimana target utama dari pukat dorong adalah udang yang juga termasuk biota demersal. Hal ini diperkuat oleh Vianita et al. (2014) bahwa Ikan Layur (Trichiurus lepturus) merupakan ikan demersal dan salah satu komoditas yang banyak ditemukan di pantai-pantai Jawa. Ikan Layur adalah ikan perairan laut yang mudah dikenal dari bentuk tubuhnya yang panjang dan ramping. Ikan Layur dewasa pada umumnya mencari makan dekat permukaan perairan sepanjang siang hari dan migrasi ke dasar perairan saat malam.

Hasil tangkapan sampingan yang memiliki nilai ekonomis tinggi misalnya Ikan Bawal Putih (Pampus argenteus), Sotong (Sepia sp.), Cumi (Photololigo sp.). Namun terdapat beberapa jenis tangkapan yang cenderung langsung dibuang kembali ke perairan selama proses penangkapan ikan (discards). Selain itu, jenis ikan sampingan lainnya yang memiliki ukuran kecil (juvenil) pun tak bisa dimanfaatkan secara optimal karena harganya menjadi murah. Menurut FAO (2011) pembuangan hasil tangkapan ke perairan memiliki dampak tertentu yang akan ditimbulkan. Dampak tersebut antara lain terjadi perubahan ekologi rantai makanan dengan membuang ikan mati atau ikan yang mungkin tidak bertahan hidup, termasuk pemborosan ikan karena membuang hasil discards, serta terjadi penangkapan ikan yang tidak berkelanjutan (unsustainable fishing). Pada penelitian Gisbert dan Lopez (2008) disebutkan bahwa tingginya hasil tangkapan sampingan memberikan efek penting pada komposisi spesies, dominasi, dan dinamika populasi dari spesies tangkapan sampingan tersebut. Jika jumlah tangkapan discards tinggi dan sebagian besar terdiri dari ikan juvenil (under-sized individuals) sehingga menimbulkan tingginya tingkat kematian ikan juvenil, maka akan berdampak pada berkurangnya recruitment individu baru serta mengurangi potensi pemijahan (potencial spawning) yang diharapkan.

\section{d. Distribusi Ukuran Hasil Tangkapan Sampingan (Bycatch) Pukat Dorong}

Berdasarkan hasil penelitian maka diperoleh hasil bahwa sebaran ukuran Ikan Layur adalah (Trichiurus lepturus) adalah 71-360 dan modus 177-211. Sebaran ukuran Ikan Kempar (Secutor ruconius) 33-95 mm, modus 43-51 mm. Ikan Kembung (Rastrelliger sp.) 51-151 mm, modus 120-136 mm. Ikan Tunul (Sphyraena jello) 111193 mm, modus 146-162 Bawal Putih (Pampus argenteus) 46-225 mm, modus 46-83 mm. Sedangkan Ikan Gerabah (Otolithes argenteus) 69-280 mm, modus 119-167 mm. menurut penelitian Nugroho et al. (2015) ukuran tersebut tergolong belum layak tangkap karena $<\mathrm{Lm}$.

Ukuran pertama kali (L50\%) tertangkap hasil tangkapan sampingan pukat dorong diketahui yaitu L50\% untuk Ikan Layur (T. lepturus) 170 mm. Ukuran L50\% Ikan Layur (T. lepturus) $<1 / 2$ L $\infty$ sehingga dapat dikatakan belum layak tangkap karena dikhawatirkan terjadi growth overfishing. Hal ini diperkuat oleh penelitian Udoh dan Ukpatu (2017) menunjukan bahwa usaha penangkapan ikan oleh pushnet mengalami kelebihan tangkap (overfishing), dimana 85\% hasil tangkapan terdiri dari udang (tujuh spesies udang) dengan 14\% bycatch. Bycatch umumnya terdiri dari ikan juvenil (total length: 0,32-46 cm).

Kondisi penangkapan hasil bycatch juvenil dapat dikurangi dengan menaikan ukuran mesh size jaring pukat dorong. Ukuran mesh size yang semakin besar diharapkan agar ikan-ikan kecil yang belum layak tangkap dapat lolos. Ukuran mesh size yang digunakan pada alat tangkap bila ditingkatkan akan memungkinkan udang kecil dan ikan jevenil untuk melepaskan diri serta menurunkan tekanan pada operasi penangkapan. Hal ini dapat meningkatkan recruitment idividu baru untuk tumbuh dan berkembang demi menjamin ketersediaan sumber daya yang keberlanjutan (sustainability). 


\section{KESIMPULAN}

Berdasarkan hasil penelitian ini dapat diambil kesimpulan yaitu pengoperasian pukat dorong meliputi proses setting, pushing, dan hauling selama 6 jam pada kedalaman 5-12 meter sekitar 2 mil dari bibir pantai dengan nilai B/C Ratio yaitu 1,63 yang berarti usaha tersebut layak untuk dijalankan. Komposisi hasil tangkapan berdasarkan berat yaitu 39,84\% tangkapan utama dan 60,16\% tangkapan sampingan. Hasil tangkapan sampingan yang mendominasi yaitu Ikan Layur (Trichiurus lepturus), Ikan Kempar (Secutor ruconius), Ikan Kembung (Rastrelliger sp.), dan Ikan Tunul (Sphyraena jello). Distribusi ukuran beberapa jenis ikan tangkapan sampingan pukat dorong di Tambak Lorok, Semarang merupakan ukuran ikan yang belum layak tangkap karena $<\mathrm{Lm}$ dan nilai $\mathrm{L} 50 \%<1 / 2 \mathrm{~L} \infty$.

\section{UCAPAN TERIMA KASIH}

Penulis mengucapkan terimakasih kepada Ir. Siti Rudiyanti, M.Si dan Dra. Niniek Widyorini, MS sebagai penguji yang telah memberikan kritik dan masukan dalam penelitian ini serta semua pihak yang telah memberikan dukungan.

\section{DAFTAR PUSTAKA}

Alverson, DL., MH. Freeberg, SA. Murawski, dan JG. Pope. 1994. A Global Assessment of Fisheries Bycatch and Discards. FAO (Food and Agriculture Organization of the United Nations). Fisheries Technical Paper. No. 339. FAO: Rome. 233p.

Ardill, D., D. Itano dan R. Gillett. 2011. A Review of Bycatch and Discard Issues in Indian Ocean Tuna Fisheries. Smartfish Working Papers. Commission De L'Ocean Indien (IOTC-2012-WPEB08-INF20)

Astuti, SP., A. Ghofar., Suradi WS., dan B. Nugraha. 2016. Jenis dan Distribusi Ukuran Ikan Hasil Tangkap Sampingan (By Catch) Rawai Tuna yang Didaratkan di Pelabuhan Benoa Bali. Diponegoro Journal of Maquares. 5 (4): 453-460

Briand, C., B. Sauvaget, P. Girard, D. Fatin, dan L. Beaulaton. 2012. Push Net Fishing seems to be Responsible for Injuries and Post Fishing Mortality in Glass Eel in the Vilaine Estuary (France) in 2007. Journal of Knowledge and Management of Aquatic Ecosystems: 404 (02)

FAO. 2011. International Guidelines on Bycatch Management and Reduction of Discards. Rome/Roma, FAO. 73 pp.

2013. Fishing Gear Types Push Net. FAO Fisheries and Aquaqulture Departement.

Gisbert, E. dan MA. Lopez. 2008. Impact of Glass Eel fishery on By-Catch Fish Species: A Quantitative Assessment. Journal of Hydrobiologia. 602: 87-98

Kelleher, K. 2005. Discards in the World's Marine Fisheries: An Update. Food and Agriculture Organization of the United Nations. Rome: Italy. FAO Fisheries Technical Paper No. 470

Kusuma, AP., D. Wijayanto, dan ADP. Fitri. 2017. Analisis Teknis dan Finansial Usaha Alat Tangkap Sodo (Push Net) dengan Target Penangkapan Udang yang Berpangkalan di Desa Bedono dan Desa Timbulsloko, Kecamatan Sayung, Kabupaten Demak. Journal of Fisheries Resources Utilization Management and Technology. 6 (4): 341-351

Nugraha, B., dan B. Setyadji. 2013. Kebijakan Pengelolaan Hasil Tangkapan Sampingan Tuna Longline di Samudera Hindia. Jurnal Kebijakan Perikanan Indonesia. 5 (2): 67-71

Nugroho, NA., A. Rosyid, ADP. Fitri. 2015. Analisis Indeks Keanekaragaman, Indeks Dominasi dan Proporsi Hasil Tangkapan Non Target Pada Jaring Arad Modifikasi di Perairan Kabupaten Kendal. Journal of Fisheries Resources Utilization Management and Technology. 4 (1): 1-11

Peraturan Menteri Kelautan dan Perikanan No. 71 Tahun 2016 Tentang Jalur Penangkapan Ikan dan Penempatan Alat Penangkapan Ikan di Wilayah Pengelolaan Perikanan Negara Republik Indonesia

Saputra, SW., Djuwito, A. Rutiyaningsih. 2013. Beberapa Aspek Biologi Udang Jerbung (Penaeus merguiensis) di Perairan Pantai Cilacap Jawa Tengah. Journal of Management of Aquatic Resources. 2 (3): 47-55

Slavin, J.W. 1982. Utilization of the Shrimp By-catch, In Fish By-Catch from the Sea. Food and Agriculture Organization of the United Nations. Rome: Italy. Fishery Industries Div. eng. 21-28 pp

Udoh, JP. dan JE. Ukpatu. 2017. First Estimates of Growth, Recruitment Pattern and Length-at-First-Capture of Nematopalaemon hastatus (Aurivillius, 1898) in Okoro River Estuary, Southeast Nigeria. AACL Bioflux. 10 (5): 1074-1084

Wahju, RI. 2012. Kajian Perikanan Trawl Demersal: Evaluasi Tiga Jenis Bycatch Reduction Device (BRD). [Tesis] Diterbitkan. Institut Pertanian Bogor

Wahyuni, I., A. Solichin, dan SW. Saputra. 2017. Beberapa Aspek Biologi Udang Putih (Penaeus indicus) di Perairan Sebelah Utara Brebes dan Tegal, Jawa Tengah. Journal of Fisheries Science and Technology (IJFST). 13 (1): 38-44

Widodo, AA., BI. Prisantoso, dan RT. Mahulette. 2010. Jenis dan Distribusi Ukuran Ikan Hasil Tangkap Sampingan (Bycatch) Pada Perikanan Tuna di Samudera Pasifik. Badan Riset Kelautan dan Perikanan Kementerian Kelautan dan Perikanan: Jakarta 
Zarochman., K, Isao., dan Indriani. 2009. Classification and Distribution of Fishing Gears in Indonesia. Ministry of Marine Affairs and Fisheries, Directorate General of Capture Fisheries in Cooperation with Japan International Cooperation Agency (JICA): Semarang

\section{LAMPIRAN}

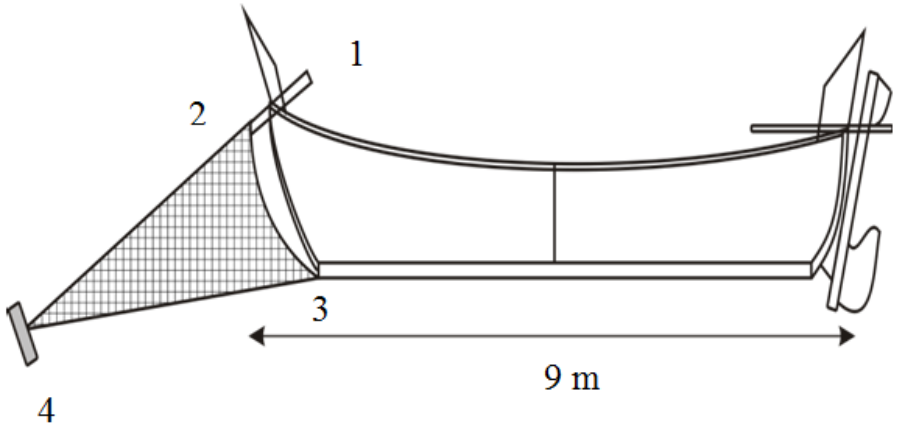

(a) Tampak samping

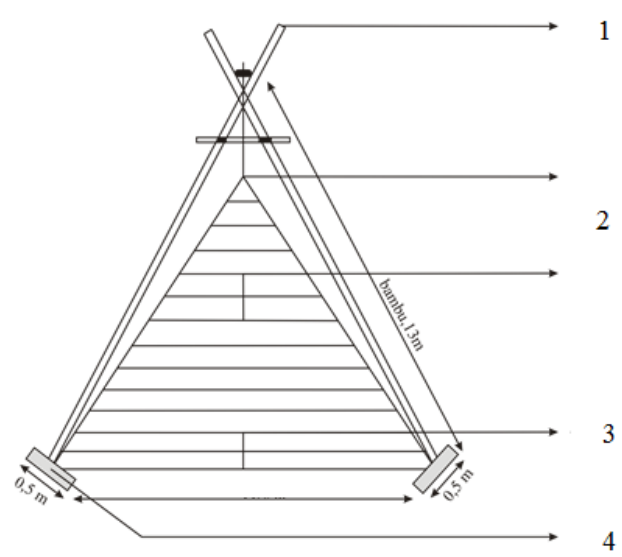

(b) Tampak depan

Alat Tangkap Pukat Dorong (Pushnet)

Keterangan:

1. Tangkai bambu dengan panjang 8,5-14 meter

2. Mulut jaring dengan ukuran mesh size 2 inci

3. Kantong dengan ukuran mesh size $0,25-1,5$ inci

4. Sepatu (Shoes of bamboo) 